\title{
The effect of preserved stapedial superstructure on hearing improvement
}

\author{
Authors' Contribution \\ A-Study Design \\ B-Data Collection \\ C-Statistical Analysis \\ D-Data Interpretation \\ E-Manuscript Prepara
F-Literature Search \\ Aleksandra Boroń ${ }^{\mathrm{ABE}}$, Agnieszka Wiatr ${ }^{\mathrm{CDE}}$, Jacek Składzień ${ }^{\mathrm{D}}$, Maciej Wiatr ${ }^{\mathrm{ADEF}}$ \\ Department of Otolaryngology Collegium Medicum of Jagiellonian University in Cracow, Poland; Head: Prof. Jacek Składzień MD PhD \\ G-Funds Collection
}

Article history: Received: 28.09.2019 Accepted: 25.11.2019 Published: 26.11.2019

ABSTRACT: $\quad$ Backgrounds: Ossiculoplasty can be carried out in a number of ways, depending on the anatomical and functional conditions encountered during otosurgery and the experience of a given centre.

The objective: The objective of the study was to analyse treatment effects in terms of postoperative hearing improvement in patients with chronic otitis media, with a particular emphasis on stapedial superstructure preservation.

Methods: The records of 294 consecutive patients undergoing their first ENT surgery due to chronic otitis media at the Department of Otolaryngology in Cracow, in 2009-2013 were analysed. In order to assess the role of preserved stapedial superstructure, 96 patients were eligible for further analysis.

Results: The analysis points to a significant hearing improvement after ossiculoplasty with the preserved stapedial superstructure as compared with the patients after footplate mobilisation. On the other hand, the research results point to significantly smaller hearing improvement in those patients, in whom only stapes was preserved, as compared with those, in whom a more extensive reconstruction of the ossicular chain was possible.

Conclusion: The air-bone gap measured before otosurgery often fails to reflect the extent of abnormalities and cannot, therefore, be considered as the only prognostic factor for postoperative hearing improvement.

KEYWORDS: chronic otitis media, stapedial superstructure, tympanoplasty

\section{INTRODUCTION}

Optimisation of surgical management in otology has always been an important issue. Different centres prefer various surgical approaches to the temporal bone, in particular regarding the preservation and potential reconstruction of the posterosuperior wall of the external auditory canal and tympanoplasty or ossiculoplasty.

The aims of ear surgery involve removing abnormalities, improving the function of the Eustachian tube and reconstruction of bone conduction pathway. Another objective is, if clinically feasible, to reconstruct the posterosuperior wall of the external auditory canal in patients undergoing open tympanoplasty. Tympanoplasty procedure may also involve canaloplasty, myringoplasty, and - in the event of damage to the auditory ossicles - ossiculoplasty.

The aim of ossiculoplasty is to reconstruct and restore normal anatomical relationships between the auditory ossicles. It is usually performed along with myringoplasty. There is a number of surgical techniques applicable to ossiculoplasty, depending on the structural and functional status of the middle ear and experience of a surgeon. However, the key determinant of the ossicle reconstruction method is the degree of damage. Ossiculoplasty can be performed under local or general anaesthesia. Local anaesthesia offers an advantage of a visual and verbal contact between the patient and the surgeon during surgery, and an associated possibility to perform an intraoperative subjective assessment of hearing improvement. Should the improvement be unsatisfactory, there is a possibility to directly reposition the ossicular chain and re-establish its continuity. A number of ossiculoplasty classifications are available. Each of them emphasizes the role of preserved and mobile stapes in ensuring hearing improvement. Zini proposed a classification of ossiculoplasty procedures depending on the location of damage within the ossicular chain [1]. Fisch described a number of basic situations characterised by the preservation of different ossicles, proposing an alternative approach to re-establishing the continuity of the ossicular chain in each of the described situations.

In his classification of ossiculoplasty, Fisch identifies three groups of patients depending on the expected functional outcome [2]. The prognosis is the poorest in patients in whom only stapes is preserved out of the entire ossicular chain. The expected postoperative air-bone gap in these patients is approximately $30 \mathrm{~dB}$. The functional prognosis depends on the air-bone gap, pressure equalisation ability of the Eustachian tube, wound healing and absence of effusion in the tympanic cavity $[3,4]$.

\section{AIM}

To perform a prospective analysis of functional outcomes in patients with chronic otitis media treated surgically at the Depart- 
ment, with particular emphasis on the status of the stapedial superstructure.

\section{MATERIALAND METHODS}

Medical records of 294 consecutive patients undergoing their first ENT procedure due to chronic otitis media at the Department of Otolaryngology, Collegium Medicum of the Jagiellonian University in Kraków in 2009-2013 were reviewed.

The youngest patient was 6 , and the oldest was 80 years old. The mean age was 40.84 years. A total of 160 women and 134 men were enrolled. Transcanal approach was chosen in 146 (49.66\%) cases, whereas retroauricular approach was chosen in 148 (50.34\%) cases.

Closed tympanoplasty was performed in 216 patients, whereas 78 patients underwent open tympanoplasty. The extent of surgery was limited to the tympanic cavity only in 60 cases. In order to access and properly visualise the disease-affected middle ear cavity, attico-antro-mastoidectomy was performed in 120 patients (Fig. 1.). In 14 cases, due to significantly advanced disease, the treatment involved radical ear surgery without Eustachian tube closure. This subset was excluded from further analyses due to a low number of cases.

Perichondrium was the most often used for tympanic membrane reconstruction. Temporalis fascia was used less often. Cartilageperichondrial composite graft was used in a few cases (Fig. 2.).

Hearing improvement was defined as closing the air-bone gap (at $500 \mathrm{~Hz}, 1000 \mathrm{~Hz}$ and $2000 \mathrm{~Hz}$ ) as a result of surgically-induced structural improvement confirmed postoperatively in an ENT assessment. The assessment was based on audiometry testing carried out directly prior to surgery as well as at 6 and 12 months postoperatively. Analysing treatment outcomes, subsets of patients were identified, depending on the ossicular chain reconstruction type.

In order to assess the role of the preserved superstructure of stapes, 96 patients were eligible for further analysis, divided into 3 subsets (Tab. I.):

- tympanic graft placed on intact stapes;

- tympanic graft placed on stapedial footplate (cartilage palisade between the footplate and the tympanic graft);

- modelled incus placed on intact stapes.

The results were analysed statistically. When interpreting the results of the observations, the results were extrapolated onto all patients with otitis media undergoing surgical treatment at the Department during the predefined timeframe.

\section{RESULTS}

The results of 96 patients at the age range of 17 to 74 years were analysed. The group consisted of 51 women and 45 men classified into 3 subsets, which differed in the extent of damage to the ossic-
Tab. I. Study sample characteristics by subset.

\begin{tabular}{|lll|}
\hline SUBSET & $\begin{array}{l}\text { NUMBER OF } \\
\text { PATIENTS }\end{array}$ & TYPE OF OSSICULOPLASTY \\
\hline 1 & 32 & tympanic graft placed on intact stapes \\
\hline 2 & 38 & $\begin{array}{l}\text { tympanic graft placed on stapedial footplate (cartilage } \\
\text { palisade between the footplate and the tympanic graft) }\end{array}$ \\
\hline 3 & 26 & modelled incus placed on intact stapes \\
\hline
\end{tabular}

Tab. II. Mean air-bone gap prior to treatment in analysed subsets.

\begin{tabular}{|lll|}
\hline SUBSET NO. & XO & SDO \\
\hline 1. & 32.08 & 10.32 \\
\hline 2. & 38.68 & 10.36 \\
\hline 3. & 33.28 & 11.25 \\
\hline
\end{tabular}

Tab. III. Mean air-bone gap 6 months postoperatively in analysed subsets.

\begin{tabular}{|lll|}
\hline SUBSET NO. & $\mathrm{X} 6$ & SD 6 \\
\hline 1. & 26.77 & 10.76 \\
\hline 2. & 35.26 & 9.77 \\
\hline 3. & 25.98 & 6.83 \\
\hline
\end{tabular}

Tab. IV. Mean air-bone gap at 12 months postoperatively in analysed subsets.

\begin{tabular}{|lll|}
\hline SUBSET NO. & $\mathrm{X} 12$ & SD 12 \\
\hline 1. & 25.10 & 10.99 \\
\hline 2. & 35.44 & 14.35 \\
\hline 3. & 25.33 & 7.39 \\
\hline
\end{tabular}

ular chain and the resulting reconstruction technique. The longterm functional effect, defined as the change in the mean air-bone gap, was assessed for the 3 subsets and comparisons were made. The three assessment time points included baseline (T0), as well as at 6 and 12 months postoperatively.

The following abbreviations were used:

$\mathrm{X}$ - mean air-bone gap,

$\mathrm{X} 0$ - mean air-bone gap prior to treatment,

X6 - mean air-bone gap at 6 months postoperatively,

$\mathrm{X} 12$ - mean air-bone gap at 12 months postoperatively,

$\mathrm{SD}$ - standard deviation.

The ANOVA for the baseline status yielded the results as shown in Tab. II., $\mathrm{P}<0.05$.

Our measurements confirmed that the mean air-bone gap differed significantly between the subsets at baseline (T0 time-point). This means that prior to treatment there had already been significant differences in the air-bone gap between the subsets, which reflected the extent of middle ear damage at baseline.

The mean air-bone gap in subset 2 was significantly larger than in the remaining subsets. This means that due to the most severe damage of the ossicular chain in subset 2 , where only mobile stapedial footplate was present, the air-bone gap was the largest, compared to the two remaining subsets. The mean air-bone gap in subset 1 was significantly larger than in subsets with the pre- 
served ossicular chain. This means that the preoperative air-bone gap was significantly larger in patients in whom only the stapes bone was preserved, than in those with less severe damage to the ossicular chain.

This finding confirms the association between the degree of hearing loss, expressed as the extent of damage to the ossicular chain and the amount of cochlear reserve (air-bone gap). The ANOVA for the air-bone gap in individual subsets at 6 months postoperatively yielded the results as shown in Tab. III., $\mathrm{P}<0.05$.

The analysis demonstrated that the mean air-bone gaps differed between the subsets $(\mathrm{P}<0.05)$. The mean air-bone gap in subset 2 was significantly larger than in other subsets (just as it was at baseline). The above finding confirms the role of absent stapedial superstructure as a negative prognostic factor in assessing hearing improvement at 6 months following tympanoplasty.

The mean air-bone gap in subset 1 was significantly larger than in subsets with the fully preserved ossicular chain. The above finding confirms a significant association between the hearing improvement and the status of the ossicular chain, indicating that the best functional outcomes are achieved in patients with the least damage to the auditory ossicles and their preserved continuity. The ANOVA for the air-bone gap in individual subsets at 12 months postoperatively yielded the results as shown in Tab. IV., $\mathrm{P}<0.05$.

There were significant differences in the mean air-bone gaps between the subsets. The mean air-bone gap in subset 2 was significantly larger than in all other subsets. This confirms little effect of ossiculoplasty in patients with damaged stapes.

The mean air-bone gap in subset 1 was significantly larger than in subsets with the preserved ossicular chain and significantly smaller than in subset 2. Longer follow-up of 12 months demonstrated a significantly better hearing improvement after ossiculoplasty in patients with preserved stapedial superstructure as compared to those with mobile stapedial footplate, yet without the superstructure.

On the other hand, the current findings emphasize significantly smaller hearing improvement in patients with preserved stapes bone only, as compared to those, in whom a more effective ossicular chain reconstruction was possible.The ANOVA for timedependence of the air-bone gap size was carried out in an attempt to ascertain whether the changes in the mean air-bone gap in each subset observed at 6 and 12 months were and remained significant.

The within-group design was used to assess changes in the airbone gap in each subset (Tab. V.).In subset 1 , there were no significant differences between the mean air-bone gap size at 6 and 12 months as compared to baseline.

In subset 2 there were no significant differences between the mean air-bone gap size at 6 and 12 months as compared to baseline, which indicates no surgically-induced hearing improvement.

The results observed in subsets 1 and 2 unequivocally confirm that severe damage to the ossicular chain with only stapes bone (or only

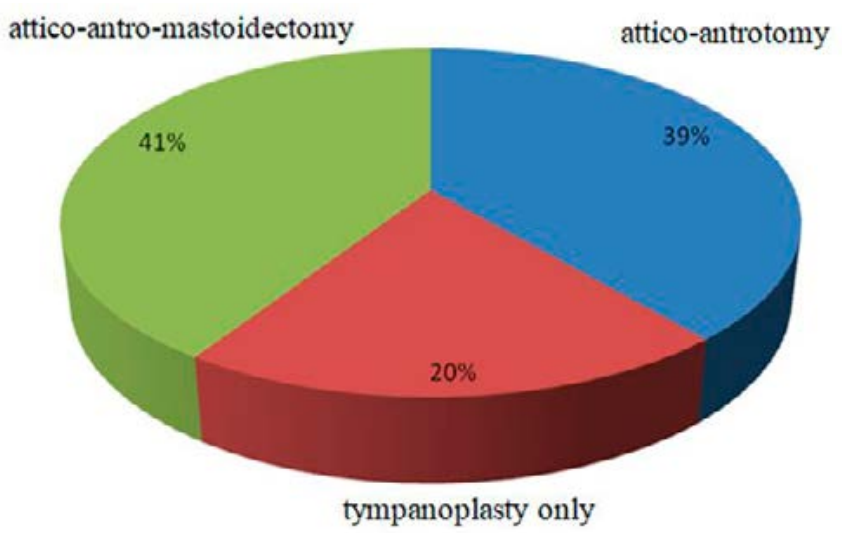

Fig. 1. The extent of temporal bone surgery.

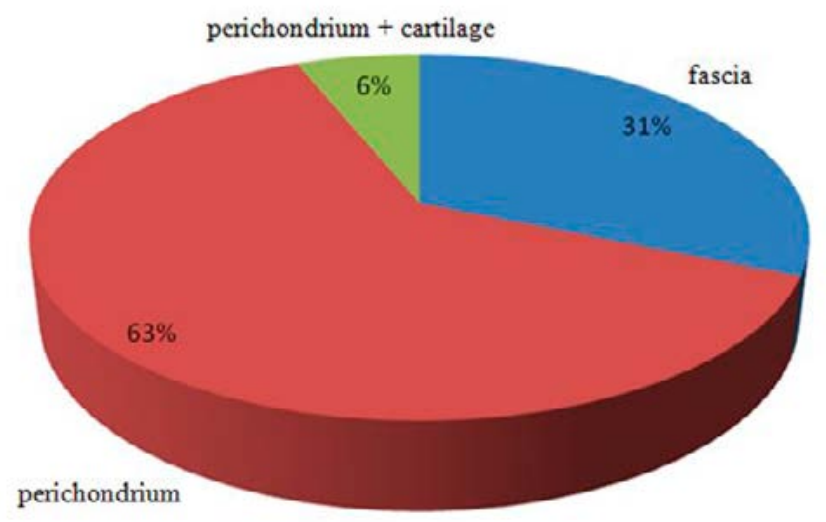

Fig. 2. The frequency of using various graft types in tympanoplasty.

stapedial footplate) preservation is often associated with no functional improvement after middle ear surgery. Radical excision of lesions to achieve dry ear should be the priority in those patients.

Using an autologous modelled ossicle (incus), placed on the head of the preserved and mobile stapes (subset 3 ) to re-establish the continuity of the ossicular chain resulted in a significant change of the air-bone gap from baseline to month six postoperatively $(P=0.046)$, which supports this reconstructive technique. In the same subset, there were no significant differences in the mean airbone gap between 6 and 12 months postoperatively, which demonstrates sustained effect of surgically induced hearing improvement.

The use of modelled incus resulted in significant hearing improvement.

\section{DISCUSSION}

Our observations show that in patients who did not need ossiculoplasty as well as those in whom bone destruction enabled using long columella technique or partial ossicular replacement prosthesis (PORP), the mean air-bone gap values at baseline fell in the range of $24.77-31.87 \mathrm{~dB}$. The mean postoperative air-bone gaps in the discussed subsets were significantly better than in the subsets where due to the extensive damage to the ossicular chain and local disease process, only myringostapedopexy was possible. The 
Tab. V. Mean air-bone gap at baseline (surgery day) as well as at 6 and 12 months postoperatively for each analysed subset. SD-standard deviation.

\begin{tabular}{|c|c|c|c|c|c|c|}
\hline $\begin{array}{l}\text { TIME FROM SURGERY } \\
\text { (MONTHS) }\end{array}$ & $\begin{array}{l}\text { AIR-BONE GAP } \\
\text { SUBSET } 1\end{array}$ & SD SUBSET 1 & $\begin{array}{l}\text { AIR-BONE GAP } \\
\text { SUBSET } 2\end{array}$ & SD SUBSET 2 & $\begin{array}{l}\text { AIR-BONE GAP } \\
\text { SUBSET } 3\end{array}$ & SD SUBSET 3 \\
\hline 0 & 32.08 & 10.32 & 38.68 & 10.36 & 33.28 & 11.25 \\
\hline 6 & 26.77 & 10.76 & 35.26 & 9.77 & 25.98 & 6.83 \\
\hline 12 & 25.1 & 10.99 & 35.44 & 14.35 & 25.33 & 7.39 \\
\hline
\end{tabular}

above findings emphasize the crucial role of proper diagnosis and thorough eligibility assessment before performing elective surgery [5-9]. At the same time, they indicate that with less advanced ossicular pathology, the air-bone gap is not always an accurate predictor of expected postoperative hearing improvement, which is a novel finding.

At the stage of treatment planning and assessing eligibility for surgery, other signs and symptoms become crucial as potential predictors of hearing improvement. It is exemplified in a prognostic classification proposed by Bellucci [10]. The author emphasizes the role of such factors as dry ear, incidence and type of effusion, Eustachian tube patency, clinical response to medical treatment of flare-ups, and concomitant structural abnormalities.

If severe damage to ossicular chain is found intraoperatively, with only stapes preserved, and in particular if stapedial superstructure is also damaged, a single-stage reconstruction does not offer satisfactory effect $[6,8,11]$. Radical excision of pathological lesions should be a priority in these patients. Once it is accomplished, reconstructive surgery can be attempted, often as the second step of a two-stage procedure. In an attempt to restore proper anatomical relationships, a potential reconstruction of the posterosuperior wall of the external auditory canal should also be considered [12].

The amount of hearing improvement decreases with the increasing extent of damage to the ossicular chain, which was also confirmed by the current analysis [13-15]. The least favourable effect was observed in patients with damage to the stapedial superstructure. As confirmed by other authors, preservation of intact stapes is of key importance in hearing improvement, as it offers a possibility to use modelled autologous incus and placing it on the stapes under the reconstructed tympanic membrane [14-17]. Partial ossicular replacement prosthesis (PORP) can be used in such cases.

It should be noted that in cases with severe damage to the ossicular chain, the preoperative air-bone gap may be smaller than the

\section{REFERENCES}

1. Zini C., Sanna M., Bacciu S., Bortesi G., Delogu P. et al.: Własne doświadczenia w leczeniu mikrochirurgicznym perlaków ucha środkowego. Otolaryngol Pol., 1985; 39(2): 110-119.

2. Fisch U.: Tympanoplastyka, Mastoidektomia i chirurgia strzemiączka. Elsevier Urban \& Partner. Wrocław 2004: 45-116

3. Huettenbrink K.: New Developments in Ossicular Reconstruction. Mediterr. J Otol., 2008; 4(suppl. 1): 37.

4. Aldosari B., Thomassin J.M.: Audiological results of endoscopic surgical repair of the long process of incus. World J Otorhinolaryngol Head Neck Surg., 2017; 3(3): 148-152. DOI: 10.1016/j.wjorl.2017.08.004.

5. Sarmento K.M.A. Jr, de Oliveira C.A.C.P., Sampaio A.L.L., Sales A.F.: Erosion of the long process of the incus with incomplete ossicular discontinuity in simple postoperative one. It is caused by involvement of pathological lesions in sound transmission between the tympanic membrane and the oval window.

It is believed that hearing improvement may not be achieved in approximately $60 \%$ of patients with damaged stapedial superstructure [18-19].

In the analysed subset, a cartilage palisade was formed on the stapedial footplate. These patients, however, did not achieve a significant change in the mean air-bone gap.

Currently, a number of prostheses are available to be placed on the stapedial footplate, in order to ensure a complete reconstruction of the ossicular chain. The presented results, supported with long-term clinical experience, demonstrate that the reconstruction of the entire ossicular chain is still a current issue in otologic surgery.

Here, it should be mentioned that, according to many authors, otologic surgery outcomes tend to worsen with time [20-21]. Very good outcomes of ear surgery measured with the closure of the air-bone gap, are no longer observable in the follow-up assessments after a dozen or more years.

\section{CONCLUSIONS}

1. The size of the air-bone gap assessed prior to surgery may not reflect the severity of disease-induced damage and cannot, therefore, be used as the only prognostic factor of postoperative hearing improvement;

2. Preservation of an intact, fully mobile stapes is the key for hearing improvement after middle ear surgery;

3. The presence of only the stapedial footplate is a negative prognostic factor of hearing improvement after tympanoplasty.

chronic otitis media: Should we reconstruct or leave it be? Clin Otolaryngol., 2018; 43(1): 300-305. DOI: 10.1111/coa.12974.

6. Bulğurcu S., Arslan İ.B., Dikilitaş B., Çukurova İ.: Relation between Ossicular Erosion and Destruction of Facial and Lateral Semicircular Canals in Chronic Otitis Media. Int Arch Otorhinolaryngol., 2017; 21(3): 239-242. DOI: 10.1055/s-0036-1592417.

7. Hess-Erga J., Engelen B.L.H.J., Vassbotn F.S.: Cartilage island on stapes: autologous PORP in the hypoventilated middle ear. Eur Arch Otorhinolaryngol., 2017; 274(4): 1859-1864. DOI: 10.1007/s00405-016-4429-z.

8. Park M., Han S., Choi B.Y., Chang S.O., Kim C.S. et al.: Incus footplate assembly: Indication and surgical outcome. Laryngoscope., 2016; 126(11): 2569-2573. DOI: 10.1002/lary.25908. 
9. Lüers J.C., Schwarz D., Anagiotos A., Gostian A.O., Beutner D. et al.: Long-term Follow-up Study of the Sandwich Cartilage Shoe Technique in Cases of Insecure Stapes Footplate. Otol Neurotol., 2016; 37(7): e197-202. DOI: 10.1097/MAO.0000000000001093.

10. Bellucci R.J.: Selection of cases and classification of tympanoplasty. Otolaryngol Clin North Am., 1989; 22(5): 911-926.

11. Edizer D.T., Durna Y.M., Hamit B., Demirhan H., Yigit O.: Malleus to Stapes Bone Cement Rebridging Ossiculoplasty: Why Don't We Perform Frequently? Ann Otol Rhinol Laryngol. 2016; 125(6): 445-451. DOI: 10.1177/0003489415618678.

12. Tachibana T., Kariya S., Orita Y., Nakada M., Makino T. et al.: Canal wall-down procedure with soft posterior meatal wall reconstruction in acquired cholesteatoma: focus on postoperative middle ear status. Acta Otolaryngol., 2018; 8: 1-6. DOI: $10.1080 / 00016489.2018 .1439593$.

13. Blom E.F., Gunning M.N., Kleinrensink N.J., Lokin A.S., Bruijnzeel H. et al.: Influence of Ossicular Chain Damage on Hearing After Chronic Otitis Media and Cholesteatoma Surgery: A Systematic Review and Meta-analysis. JAMA Otolaryngol Head Neck Surg., 2015; 141(11): 974-982. DOI: 10.1001/jamaoto.2015.2269. Review.

14. Wiatr M., Składzień J., Tomik J., Stręk P.: Usefulness of a ventilation tube as a partial ossicular replacement prosthesis (PORP) in ossiculoplasty in patients with chronic otitis media. Med Sci Monit., 2014; 20: 974-979. DOI: 10.12659/MSM.890447.

15. Wiatr M., Składzień J., Tomik J., Stręk P., Przeklasa-Muszyńska A.: Type II tympanoplasty in chronic cholesteatoma and granulomatous otitis media - distant results of otosurgery. Adv Med Sci., 2014; 59(1): 44-46. DOI: 10.1016/j. advms.2013.07.004.

16. Chen Z., Sun X., Zhou H., Shi H., Wu Y. et al.: Comparison of hearing results of malleovestibulopexy and total ossicular replacement prosthesis for chronic otitis media patients with a mobile stapes footplate. Ann Otol Rhinol Laryngol., 2014; 123(5): 343-346. DOI: 10.1177/0003489414526366.

17. Okada M., Gyo K., Takagi T., Fujiwara T., Takahashi H. et al.: Air-bone gap in ears with a well-repaired tympanic membrane after Type III and Type IV tympanoplasty. Auris Nasus Larynx., 2014; 41(2): 153-159. DOI: 10.1016/j. anl.2013.10.006

18. Vijayendra H., Parikh B.: Bone conduction improvement after surgery for conductive hearing loss. Indian J Otolaryngol Head Neck Surg., 2011; 63(3): 201-204. DOI: 10.1007/s12070-011-0130-0.

19. Vartiainen E., Vartiainen J.: Hearing results of surgery for chronic otitis media without cholesteatoma. Ear Nose Throat J., 1995; 74(3): 165-166, 169.

20. Eleftheriadou A., Chalastras T., Georgopoulos S., Yiotakis J., Manolopoulos L. et al.: Long-term results of plastipore prostheses in reconstruction of the middle ear ossicular chain. ORL J Otorhinolaryngol Relat Spec., 2009; 71(5): 284-288. DOI: $10.1159 / 000253487$.

21. Wiatr M., Wiatr A., Składzień J., Stręk P.: Determinants of Change in Air-Bone Gap and Bone Conduction in Patients Operated on for Chronic Otitis Media. Med Sci Monit., 2015; 21: 2345-2351. DOI: 10.12659/MSM.894087.

\begin{tabular}{|c|c|c|}
\hline & Word count: 3120 & References: 21 \\
\hline DOI: & $10.5604 / 01.3001 .0013 .5954$ & Table of content: https://otolaryngologypl.com/issue/12543 \\
\hline Copyright: & $\begin{array}{l}\text { Copyright @ } 2020 \text { Polish Society of Otor } \\
\text { Sp. z o.o. All rights reserved }\end{array}$ & gologists Head and Neck Surgeons. Published by Index Copernicus \\
\hline
\end{tabular}

Competing interests: The authors declare that they have no competing interests.

The content of the journal "Polish Society of Otorhinolaryngologists Head and Neck Surgeons" is circulated on the basis of the Open Access which means free and limitless access to scientific data.

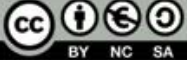

This material is available under the Creative Commons - Attribution 4.0 GB. The full terms of this license are available on: http://creativecommons.org/licenses/by-nc-sa/4.0/legalcode

Corresponding author: Aleksandra Boroń, MD, PhD; Department of Otolaryngology, Collegium Medicum of Jagiellonian University in Cracow, Poland; E-mail: olaboron@op.pl, Phone: +48 506293481

Cite this article as: Boron A., Wiatr A., Skladzien J., Wiatr M.: The effect of preserved stapedial superstructure on hearing improvement; Otolaryngol Pol 2020; 74 (1): 17-22 
